\title{
Regarding the influence of the particle size of crumb rubber from waste rubber on the physical and mechanical characteristics of reclaimed rubber
}

\author{
Dan Dobrotă $\breve{1}^{1, *}$, and Gigel Paraschiv ${ }^{2}$ \\ ${ }^{1}$ Lucian Blaga University of Sibiu, Bd-ul Victoriei 10, Sibiu, Romania \\ ${ }^{2}$ University Politehnica of Bucharest, 313 Splaiul Indepentei, Romania
}

\begin{abstract}
Thus, at present, a large amount of rubber waste cannot be higher harnessed due to recovery technologies used. Also, the requirements for new products of rubber worldwide are greater than the production capacity and the availability of raw materials. To offset this balance is necessary to improve technologies for recycling waste rubber so to can get regenerated rubber with the best mechanical physical characteristics. The main technology for obtaining the regenerated rubber is based on the rubber waste shredding and making the powder, so that it can be carried out de-vulcanization in autoclave. All the time it was monitored as the devulcanization process to be as economical and less polluting, and this requires that the sizes of the crumb rubber to be optimal. Thus, in the conducted researches was aimed to establish the particle size of crumb rubber from waste rubber so as to obtain an economical de-vulcanization, but also a reclaimed rubber with superior physical and mechanical characteristics. The organization of researches was made so that crumb of rubber waste was divided into 5 groups, bowing from crumb rubber with particle's size of $1000 \mu \mathrm{m}$ (RPS1), and reaching up to crumb rubber with particle's size of $200 \mu \mathrm{m}$ (RPS 5).
\end{abstract}

\section{Introduction}

Regarding the concerns about the reintroduction in the processes for obtaining various rubber products, rubber waste they are as old as the rubber processing industry. Over time it was manifested a distinct interest from the recovery and regeneration of waste rubber which suffered constant changes depending on the quantities required by the market and its price development [1-2]. Thus, it was found that there is a constant competition between products made from reclaimed rubber and the resources obtained from the original resources. The problem of valorification through the rubber processing from waste is an increasing topic in recent years, as a result of the general crisis of raw materials and energy, and because large quantities of rubber waste are withdrawn from economic circuit [3-5].

\footnotetext{
* Corresponding author: dobre97@yahoo.com
} 
The presence of an intense waste rubber causes environmental pollution and the removal from economic circuit of significant material resources.

For an efficient utilization of rubber waste there can be taken into account the variant in which it is converted into a material that can be returned to the manufacturing process from which they come. Such a variant is possible if the rubber waste undergoes a technological process (Fig. 1) so that by grinding and devulcanization is obtained the regenerated rubber, which can be used in the composition of various rubber products [6].
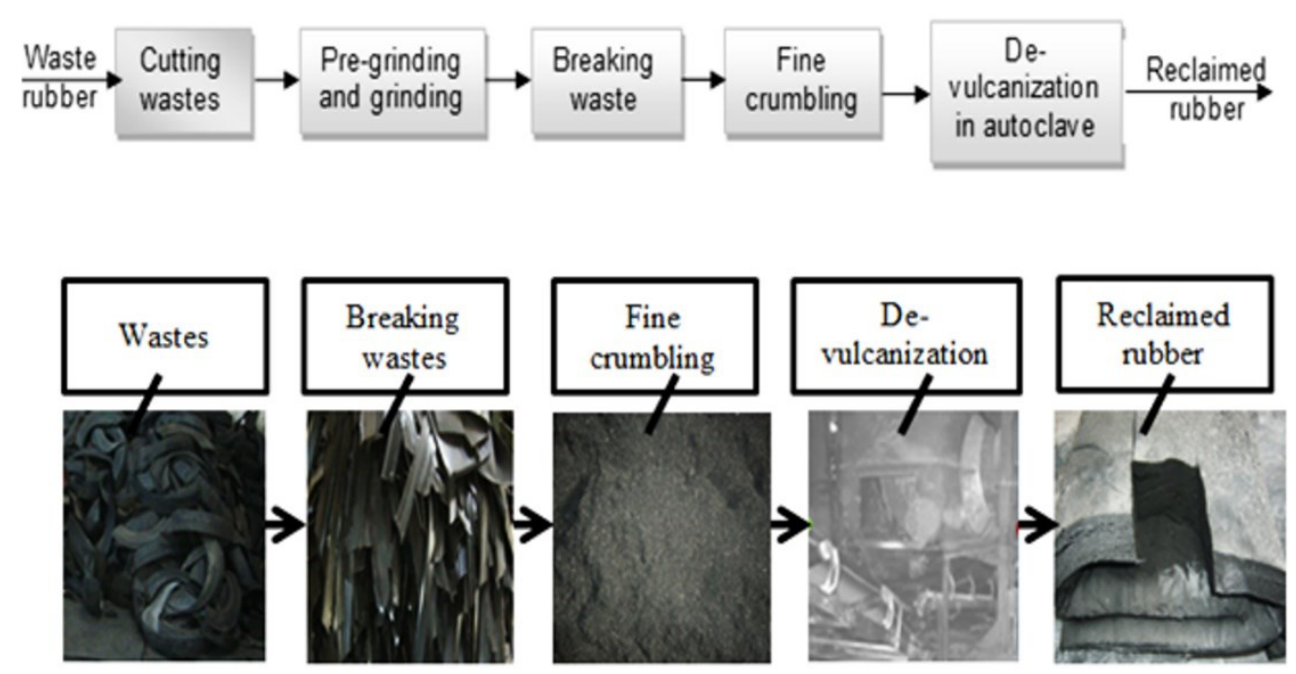

Fig. 1. Classic flow process diagram for obtaining reclaimed rubber.

Through the regeneration of waste rubber, there is obtained the reclaimed rubber, which can have a whole series of economic and technical advantages, namely [7, 8]:

- the stimulation and stability of the price are determined by broad based of raw material. It should be taken into account that at the regeneration of waste there is obtained the regenerated rubber and other components with a high economic value (textile inserts or metal);

- short mixing cycles are characteristic for compositions that include reclaimed rubber because it contains all the necessary ingredients and the swelling agents and/or the regeneration favors the mixing process;

- low power consumption at mixing is due to specific structure of reclaimed rubber. Realizing charging of and plasticizing at the reclaimed rubber proportions, mixing rubber NR type requires $20 \%$ more energy, and rubber SBR 1712 with $43 \%$ more;

- calendering is made easier due to the fact that the development of heat in the mixture bench is lower, it can work in a wide range of temperature. Even if the mixture contains regenerated rubber, it has a shorter pre-vulcanization time (Mooney) and it may be safer in processing in calender;

- calendering and rapid and uniform extrusion of the rubber is sustained by the introduction of various types of regenerated rubber in the compositions;

- the penetration of the compositions in fabric at the operations of adding rubber solution is facilitated by the presence of reclaimed rubber.

For the evaluation of the quality of reclaimed rubber, over time there have been proposed several indicators. About these indicators it can be said that some of them are antagonistic, others have become anachronistic etc., but it is always difficult to make an overall follow-up after several indicators simultaneously. 
Therefore, it has been proposed [9] a generalized indicator (QIG) defined by the equation:

$$
\mathrm{QIG}=\frac{100-C}{100} \cdot M \cdot R \cdot \frac{A}{100}
$$

where:

$\mathrm{C}-$ ash content, $\%$;

$\mathrm{M}$ - Mooney viscosity;

$\mathrm{R}$ - traction resistant, $\mathrm{N} / \mathrm{mm}^{2}$;

A - tensile elongation limit, $\%$.

In the relation of the QIG indicator is observed that are taken into account only a small number of physical-mechanical characteristics and thus in practice, to assess the quality of a product of rubber there should be more considered the physical and mechanical characteristics.

The uses of reclaimed rubber are limited by the fact that it can reduce the abrasion resistance. Breakage strength may also be adversely affected, although there are known cases (the use of regenerate from integral tire) [10] when the influence is positive. Moisture absorption of the reclaimed rubber is relatively large in comparison with the compositions of new tires and therefore its use is not recommended when water absorption is an essential criterion [10-13].

According to data presented in [4], there can be taken as guidance the following distribution of reclaimed rubber in fields of use, Table 1.

Table 1. Distribution of reclaimed rubber by the fields of use.

\begin{tabular}{|c|c|}
\hline Fields of use & Quantity used, $\%$ \\
\hline Tires & 55 \\
\hline Pressed technical articles & 19 \\
\hline Conveyor belts, belts, hoses & 7 \\
\hline Ebonite products & 6 \\
\hline $\begin{array}{c}\text { Gaskets for installation and construction, household products, } \\
\text { dispersions, adhesives, footwear etc. }\end{array}$ & 13 \\
\hline
\end{tabular}

Assortment standardization and quality of reclaimed rubber is very approximate. Selecting the type and proportions used in the manufacture of certain products is done on experimental basis depending on the demands made on the finished product [14]. It is indicated that for each case to consult the supplier specifications on qualitative indicators of the regenerated product which is offered. The obtained results with the regenerated product provided by a particular manufacturer can not expand unconditionally and the switching of the provider requires reverification of the use potential $[15,16]$.

\section{Materials and methods}

In the technological process of obtaining reclaimed rubber, two operations present an important role in achieving rubber products with superior mechanical characteristics, namely the fine grinding operation and the devulcanization operation [17, 18]. By fine grinding of waste rubber there is obtained an increase in specific surface of the particles produced which allows an improvement in devulcanization conditions in the autoclave and a possible change of the physical and mechanical characteristics of the regenerated rubber.

In the research there was considered a technological process of regeneration of waste rubber from conveyor belt reinforced with metal inserts. It was considered a waste rubber because the rubber from these products is one with superior physical and mechanical 
characteristics. Thus, in the research there were determined physico-mechanical properties of the obtained rubber taking into account the equipment and standards outlined in Table 2.

Table 2. Equipment and standards used to determine physical and mechanical characteristics.

\begin{tabular}{|c|c|c|}
\hline $\begin{array}{c}\text { Physical and mechanical } \\
\text { characteristic }\end{array}$ & Equipment & Standard \\
\hline Hardness, ${ }^{0} \mathrm{Sh}$ & $\begin{array}{l}\text { Durometer BAREISS HPE tip Shore } \\
\text { A }\end{array}$ & $\begin{array}{l}\text { SR ISO 27619-1/ } \\
2011\end{array}$ \\
\hline Elasticity, \% & Zwick 5109 & ISO 4662 / 2009 \\
\hline Viscosity Mooney $\mathrm{ML}\left(1^{\prime}+4^{\prime}\right) 100^{\circ} \mathrm{Cb}$ & Viscometer Mooney Model: TO-230 & ASTM D1646 \\
\hline Grade of rubber vulcanization & Rheometer Model: TO-220 & ASTM D 1646 \\
\hline Tensile strength, $\mathrm{N} / \mathrm{mm}^{2}$ & $\begin{array}{l}\text { Machine of Traction Lloyd } \\
\text { instruments a trademark of AMETEK } \\
\text { tip LR10K PLUS } 01 / 3052\end{array}$ & SR ISO 37:2010 \\
\hline Elongation at break, \% & $\begin{array}{l}\text { Machine of Traction Lloyd } \\
\text { instruments a trademark of AMETEK } \\
\text { tip LR10K PLUS } 01 / 3052\end{array}$ & SR ISO 37:2010 \\
\hline Residual elongation, $\%$ & $\begin{array}{l}\text { Machine of Traction Lloyd } \\
\text { instruments a trademark of AMETEK } \\
\text { tip LR10K PLUS } 01 / 3052\end{array}$ & SR ISO 37:2010 \\
\hline Tear strength, $\mathrm{N} / \mathrm{mm}$ & $\begin{array}{l}\text { Machine of Traction Lloyd } \\
\text { instruments a trademark of AMETEK } \\
\text { tip LR10K PLUS } 01 / 3052\end{array}$ & D $411507 / C$ \\
\hline Density, $\mathrm{g} / \mathrm{cm}^{3}$ & Balance SARTORIUS 2462 & $\begin{array}{l}\text { SR ISO 2781+C1/ } \\
2001\end{array}$ \\
\hline Wear, $\mathrm{mm}^{3}$ & Abrazimeter Model C5000 & ISO 11998 \\
\hline
\end{tabular}

\section{Results and discussions}

The process of obtaining reclaimed rubber is quite complex and includes multiple operations, but two of them are of particular importance, namely the grinding operation respective the de-vulcanization operation.

Both operations greatly influence the quality of reclaimed rubber. Thus, by a very fine grinding it is obtained an increase in the specific surface of the rubber particles and this may result in an improvement of the process of de-vulcanization in autoclave by better breaking of the links of the rubber.

In these circumstances, the researches aimed at establishing the influence of particle size obtained in the grinding operation on the physic-mechanical properties of reclaimed rubber.

Thus, waste rubber from conveyor belt which contains rubber with superior physicalmechanical characteristics of the type TRDZ were subjected to the regeneration. Also, it was considered a type of waste because the rubber quantity from such waste is very large and has a considerable economic value.

There were 5 groups of particles, Figure 2, obtained by grinding of tire, namely:

- RSP 1 crumb rubber with a particle size of $1000 \mu \mathrm{m}$;

- RSP 2 crumb rubber with a particle size of $800 \mu \mathrm{m}$;

- RSP 3 crumb rubber with a particle size of $600 \mu \mathrm{m}$;

- RSP 4 crumb rubber with a particle size of $400 \mu \mathrm{m}$;

- RSP 5 crumb rubber with a particle size of $200 \mu \mathrm{m}$. 


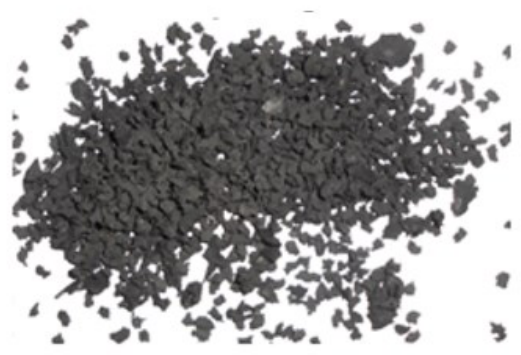

a

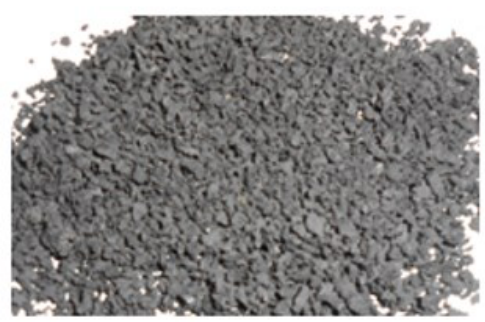

C

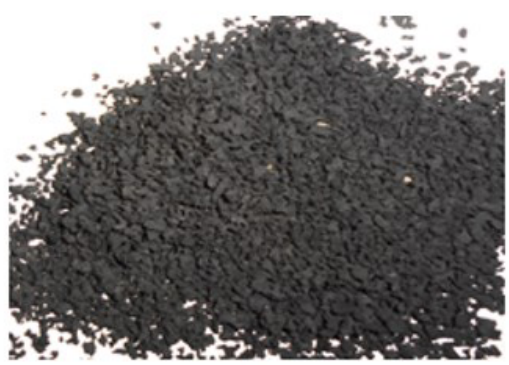

b

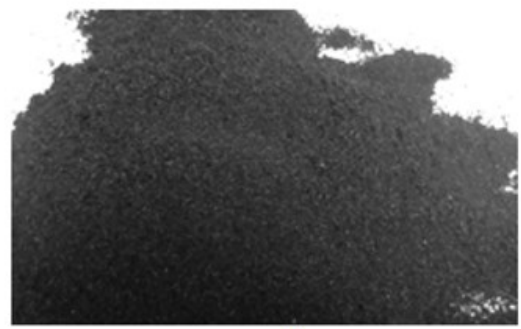

d

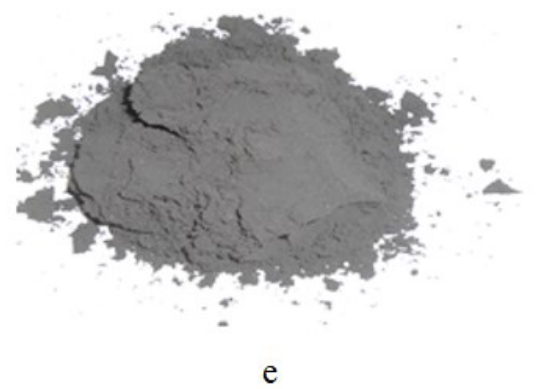

Fig. 2. The crumb rubber resulting from waste crumbling: a - crumb rubber with a particle size of $1000 \mu \mathrm{m} ; \mathrm{b}$ - crumb with a particle size of $800 \mu \mathrm{m}$; c - crumb with a particle size of $600 \mu \mathrm{m} ; \mathrm{d}$ crumb with a particle size of $400 \mu \mathrm{m}$; e - crumb with a particle size of $200 \mu \mathrm{m}$.

After fine grinding operation the five groups of particles from the waste rubber have been subjected to the operation of de-vulcanization compliance with the same technological parameters, respectively temperature, time, pressure. Following the de-vulcanization and refining there were obtained 5 types of reclaimed rubber which may enter into the composition of various rubber recipes.

The waste which was left from the conveyor belts have been monitored as the 5 kinds of reclaimed rubber to enter into the same type of rubber that is the TRDZ. This type of rubber must have good physical and mechanical characteristics because the conveyor belts are subjected to high mechanical stress and work under very heavy conditions.

To obtain a TRDZ rubber type with best characteristics it must have in composition different types of material in addition to reclaimed rubber. Thus, the composition of rubber type TRDZ, Table 3, was realized so that a batch of $320 \mathrm{~kg}$ of rubber to get into $100 \mathrm{~kg}$ of reclaimed rubber obtained from the five groups of particles (RSP 1, RSP 2, RSP 3, RSP 4, RSP 5).

Due to the fact that there were obtained five kinds of the regenerated rubber based on the particle size it was possible to obtain five kinds of rubber type TRDZ (TRDZ 1 when using reclaimed rubber from particles SRP 1, TRDZ 2 when using reclaimed rubber from 
particles SRP 2, TRDZ 3 when using reclaimed rubber from particles SRP 3, TRDZ 4 when using reclaimed rubber from particles SRP 4, TRDZ 5 when using reclaimed rubber from particles SRP 5).

Table 3. The TRDZ rubber composition using reclaimed rubber.

\begin{tabular}{|c|c|}
\hline Materials & Mass, Kg \\
\hline Regenerated rubber (RSP 1, RSP 2, RSP 3, RSP 4, RSP 5) & 100 \\
\hline Natural rubber SIR-20 & 20 \\
\hline Styrene butadiene synthetic rubber SBR & 50 \\
\hline Poly-butadiene synthetic rubber SKD ND & 30 \\
\hline Naphtha & 30 \\
\hline Carbon black HAF & 50 \\
\hline Zinc oxide ZnO & 10 \\
\hline Antioxidant 4010NA/LG(IPPD) & 5 \\
\hline Antioxidant HS/LG (TMQ) & 5 \\
\hline Stearin & 5 \\
\hline Bitumen & 20 \\
\hline Inhibitor of pre-vulcanization CTP & 5 \\
\hline Vulcanization accelerator CZ (CBS) & 5 \\
\hline Vulcanization accelerator D & 5 \\
\hline Sulfur & 10 \\
\hline Total & 350 \\
\hline
\end{tabular}

For all the five kinds of TRDZ rubber, there were determined different physical and mechanical characteristics, and the obtained values are presented in Table 4.

Table 4. Physico-mechanical characteristics for TRDZ rubber.

\begin{tabular}{|c|c|c|c|c|c|}
\hline $\begin{array}{c}\text { Physico-mechanical } \\
\text { characteristic }\end{array}$ & TRDZ 1 & TRDZ 2 & TRDZ 3 & TRDZ 4 & TRDZ 5 \\
\hline Hardness ${ }^{0}$ Sh & 72 & 70 & 68 & 66 & 64 \\
\hline Elasticity \% & 14 & 15 & 17 & 19 & 21 \\
\hline $\begin{array}{c}\text { Viscosity Mooney ML(1+4) } \\
100^{0} \mathrm{C}\end{array}$ & 76 & 77 & 79 & 80 & 83 \\
\hline Grade of rubber vulcanization & 10.8 & 11.5 & 12.3 & 12.7 & 12.9 \\
\hline Tensile strength N/mm ${ }^{2}$ & 79 & 81 & 85 & 91 & 97 \\
\hline Elongation at break \% & 361 & 367 & 378 & 386 & 392 \\
\hline Residual elongation \% & 21 & 19 & 17 & 15 & 14 \\
\hline Tear strength N/mm & 57 & 55 & 54 & 51 & 43 \\
\hline Density g/cm ${ }^{3}$ & 1.29 & 1.27 & 1.25 & 1.24 & 1.22 \\
\hline Wear mm ${ }^{3}$ & 147 & 145 & 143 & 141 & 139 \\
\hline
\end{tabular}

The results obtained in experimental research and presented in Table 4 demonstrate the following:

- the hardness of the rubber is reduced in the case where for the realization of the rubber type TRDZ is used regenerated rubber made of crumb rubber with lower dimensions;

- the influence of particle size from crumb manifests on the elasticity of rubber in the sense that for smaller particles there is achieved a greater elasticity which is a great advantage if it is sought to obtain rubber products which will be used in high temperature conditions and high mechanical stress;

- when the rubber particle size is smaller there was observed an increase in viscosity that allows the production of rubber products with superior technical features;

- rubber vulcanization degree increases with decreasing of particle size of the rubber which shows what connections occur during the vulcanization of rubber are much stronger; 
- tensile strength greatly increases with the size reduction of the rubber, and this allows the obtaining of rubber products such as tires and conveyor belts with high performance in operation;

- elongation at rupture is much higher if there is used reclaimed rubber obtained from the crumb with very small particles size, and this allows to obtain different types of products which gives up very hard if they are subjected to requests for stretching;

- the use of crumb rubber with small sizes allows to produce products with high wear resistance and in these conditions, in practice there should be used a lot of reclaimed rubber from waste rubber which are undergo to intense grinding.

\section{Conclusions}

Recycling and the regeneration of waste rubber constituted and constitute still one of the activities which must be given special attention. The research results obtained demonstrate that the transformation of waste rubber in reclaimed rubber and its use for obtaining different types of products is an effective technical solution which can have economic effects and it reduce the environmental pollution.

Through an efficient waste rubber grinding there are considerably improved the devulcanization conditions in autoclave, and this allows to obtain reclaimed rubber mixtures with superior physical and mechanical characteristics. It also requires the optimization of grinding and de-vulcanization process so there is a correlation between their technological parameters to obtain low cost, but also in order to achieve superior regeneration of various types of waste rubber.

\section{References}

1. D. Dobrotă, Journal of Adhesion Science and Technology, 27, 125 (2013)

2. J.Y. Xu, M. Shen, X.Q. Wang, C.H. Chen, Z.X. Xin, Journal of Macromolecular Science, Part B, 53, $1182(2014)$

3. J. Karger-Kocsis, L. Mészáros, Journal of Materials Science, 48, 1 (2013)

4. V. Torretta, E.C. Rada, M. Ragazzi, E. Trulli, I.A. Istrate, L.I. Cioca, L.I., Waste Management, 45, $152(2015)$

5. S. Saiwari, E. Lohyi, C. Nakason, Advanced Materials Research, 844, 437 (2014)

6. X. Sun, A.I. Isayev, Journal of Materials Science, 42, 7520 (2007)

7. D. Dobrotă, Materiale Plastice, 43, 65 (2006)

8. P. Krawczak, Express Polymer Letters, 5, 838 (2011)

9. D. Dobrotă, G. Dobrotă, Journal of Cleaner Production, An innovative method in the regeneration of waste rubber and the sustainable development http://doi.org/10.1016/j.jclepro.2017.03.022 (2017)

10. S. Ramarad, C. Ratnam, M. Khalid, A. L. Chuah, S. Hanson, Radiation Physics and Chemistry, 130, $362(2017)$

11. S. Ramarad, C.T. Ratnam, M. Khalid, A. L. Chuah, J. Appl. Polym. Sci., 132, 416 (2014)

12. P. Sae-oui, C. Sirisinha, K. Hatthapanit, Express Polymer Letters, 1, 8 (2007)

13. M. Magioli, A. Sirqueira, B. Soares, Polymer Testing, 29, 840 (2010)

14. C. Searcy, D. McCartney, S. Karapetrovic, Corporate Social Responsibility and Environmental Management, 14, 135 (2007)

15. H. Su, J. Yang, T.-C. Ling, G.S. Ghataora, S. Dirar, Journal of Cleaner Production, 91, 288 (2015)

16. B.S. Thomas, R.C. Gupta, V.J. Panicher, Journal of Cleaner Production, 112, 504 (2016)

17. A. Tripathy, D. Williams, R. Farris, Polymer Engineering \& Science, 44, 1338 (2004)

18. F. Hashim, M. Almaamori, F. HamoodInternational Journal of ChemTech Research CODEN (USA), 48, 325 (2016) 